\title{
Comparison of mineral oil and esters as cooling liquids in high voltage transformer in aspect of environment protection
}

\author{
Grzegorz Dombek ${ }^{1}$, Przemyslaw Goscinski ${ }^{1}$, and Zbigniew Nadolny ${ }^{1,{ }^{*}}$ \\ ${ }^{1}$ Poznan University of Technology, 60965 Poznan, Poland
}

\begin{abstract}
The article presents the results of computer simulation of temperature field of transformer filled with mineral oil and alternatives insulating liquids which include synthetic and natural esters. The analysis was based on the results of computer simulation of temperature field of 10 MVA distribution transformer, using the program COMSOL Multiphysics.
\end{abstract}

\section{Introduction}

Mineral oil is one of the most commonly used insulating liquid [1]. It is used in many electrical equipment, such as power transformers. The universality of application of mineral oil results from its many positive qualities and its very good recognition over the years. However, at the end of XX century, people began to use alternative insulating liquids. Restrictive requirements for safety of electrical power equipment and environmental protection were the main reason of the use of the alternative liquids.

In the late XIX century, the idea of the use of alternative liquids in the electrical power devices was founded. At that time vegetable oils, which now are called natural esters, were used as an insulating liquid in transformers.

Long term of the use of mineral oils in electrical power equipment caused the improve of them production and treatment. Satisfied identification of their properties is main reason of their application as insulating liquids in power industry. Improving manufacturing processes and treatment of mineral oils have contributed to a significant reduction of their prices, which is one of the important criteria taken into consideration by potential users of transformers. Furthermore, affordable price means that mineral oils are still the most commonly used insulation liquids, even if alternative liquids are characterized by significantly better environmental and fire properties.

Currently, natural and synthetic esters are considered as alternatives to mineral oil [2-7]. These liquids have a number of features that are recognized for their benefits, comparing to mineral oil. These characteristics are primarily ecological properties such as biodegradability and non-toxicity, and properties conditioning operational safety which include high flash and fire point and low calorific value [2, 8,9]. For this reason, when fire safety and environment protection play a key role, the use of transformers filled esters is justified solution.

\footnotetext{
*Corresponding author: zbigniew.nadolny@put.poznan.pl
} 
This applies above all electrical power equipment used in built-up areas and densely populated areas. Furthermore, companies engaged in the insuring network assets, including power transformers, are becoming increasingly aware of the fire risk associated with the use of electrical equipment insulating liquid characterized by low values of fire and flash point, which speaks in favour of esters.

On the basis of information presented above, it can be concluded that the esters, unlike mineral oil, are characterized by several positive environmental and fire properties, so that more and more willing they are used in electrical equipment, including transformers. One of the basic functions of insulating liquid is heat transport, that is generated mainly by the winding and the core [2, 10-13]. Cooling effectiveness of transformer depends on properties of used liquid, because the liquid fills significant space of the transformers [14-16]. Therefore, this paper presents a comparative analysis of the temperature field of $10 \mathrm{MVA}$ transformers filled with mineral oil and esters (synthetic and natural).

\section{Research object}

Figure 1 shows the scheme of 10 MVA distribution transformer, which was used in computer simulation of temperature field.

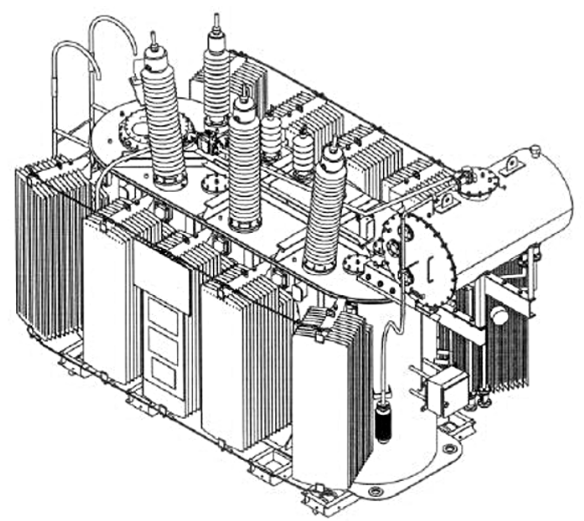

Fig. 1. 10 MVA distribution transformer model.

The transformer used ON-AN cooling type - active parts of the transformer: oil-cooled (natural flow), and the tank: air-cooled (natural convection and radiation). Furthermore, the transformer has a 11-step adjustment of the upper voltage winding in the range of $+/-16 \%$ of the rated voltage. Cooling system of the transformer is aided by ten B-520FL radiators, of which the manufacture deep-drawn sheet metal were used. Each of the radiators is equipped with four ribs with a height of $1.4 \mathrm{~m}$ and eleven ribs with a height of $1.6 \mathrm{~m}$. Simplified construction and the small number of radiators in the presented transformer helped to significantly reduce the time of computer simulation. 


\section{Computational model}

The analysis temperature field distribution can be made using following models: analytical models, numerical models, and real models. The paper presents the results of analysis of numerical models. Computational model was created (fig. 2) on the basis of object presented in chapter 2, which was a 10 MVA distribution transformer, using COMSOL Multiphysics software. The geometry of the model was simplified because the real object has a number of structural elements (e.g. conservator, bushings, control cabinet), which do not affect its thermal efficiency [17]. Table 1 shows main parameters of used model.

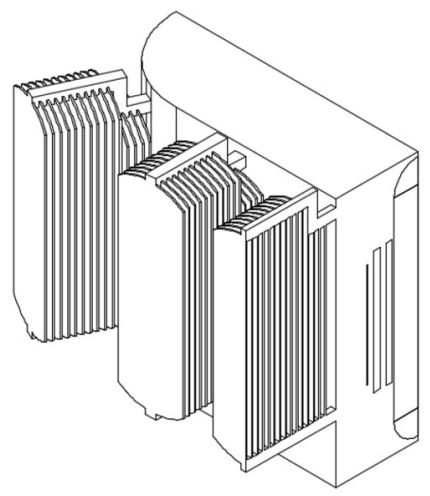

Fig. 2. 10 MVA distribution transformer computational model.

Table 1. Main parameters of the 10 MVA distribution transformer model.

\begin{tabular}{|l|l|}
\hline Rated power & $10 \mathrm{MVA}$ \\
\hline Rated voltages & HV: $115 \mathrm{kV}, \mathrm{LV}: 16,5 \mathrm{kV}$ \\
\hline Rated currents & HV: $50 \mathrm{~A}, \mathrm{LV}: 350 \mathrm{~A}$ \\
\hline Types of cooling & ON-AN \\
\hline Number of phase & 3 \\
\hline Vector group symbol & Ynd11 \\
\hline No-load current & $0.12 \%$ \\
\hline Total weight & $23800 \mathrm{~kg}$ \\
\hline Mass of insulating oil & $6400 \mathrm{~kg}$ \\
\hline No-load losses & $6600 \mathrm{~W}$ \\
\hline Load losses & $57400 \mathrm{~W}$ \\
\hline
\end{tabular}

Presented in figure 2 computational model consists of tank, lower and upper voltage winding, regulating winding and radiators. Therefore, the transformer design is symmetrical and has a symmetrical spacing of radiators along the axis. So, it was decided to modelling only a quarter of the transformer. Authors resigned from the modelling stamping ribs radiators. Mesh model was built with tetragonal and pyramidal elements, whose number does not exceed 13 million. It allowed to achieve appropriate accuracy of the obtained results, which was $0.01 \%$, and significantly reduce simulation time.

During computer simulation of insulating liquids, material parameters corresponding to the mineral oil, natural and synthetic esters were adopted. This means that in the case of mineral oil the value of heat transfer factor $\alpha$ equal to $125.70 \mathrm{~W} \cdot \mathrm{m}^{-2} \cdot \mathrm{K}^{-1}$, natural ester 111.80 $\mathrm{W} \cdot \mathrm{m}^{-2} \cdot \mathrm{K}^{-1}$, and synthetic ester $110.72 \mathrm{~W} \cdot \mathrm{m}^{-2} \cdot \mathrm{K}^{-1}$ was accepted. 
Heat transfer factor $\alpha$ is the key parameter, which describes the ability of liquid to transfer of the heat. The factor $\alpha$ considers many thermal properties, such as thermal conductivity, specific heat, viscosity, density and kinematic extension factor. All mentioned parameters have significant influence on heat transfer by the liquids.

The boundary conditions were used in the last step of the calculation. It means that ambient temperature and heat transfer factor $\alpha$ are known. It was assumed that the losses in the core and windings are heat sources. The values of these losses were determined in the result of the short-circuit attempt on presented research model, and then implemented in analysed computational model. The value of the losses was $64 \mathrm{~kW}$. Moreover, according to the standard [18] it has been adopted that the ambient temperature is $20^{\circ} \mathrm{C}$, and atmospheric pressure is $1 \mathrm{~atm}$.

In order to determine the distribution of temperature field in the transformer in COMSOL Multiphysics, Heat Transfer module was used. The module considers thermal properties of analysed liquids and type of flow. This module considers temperature dependence of thermal properties such as thermal conductivity, viscosity, density and specific heat, which determine the heat transfer in liquids. Therefore, authors have presented the results of research on the thermal properties of the insulating liquids in previous publications, presented research results were used in the simulations [19-22].

In order to receive the dependence of time, simulations were conducted in non-stationary mode. Steady state was reached after about 14 hours for all analysed cases. During the heating trials carried out on the presented research model after about 10 hours steady state was reached. The differences in the two times result from two reasons. First one is related to the fact that in the case of the real object, in order to faster obtaining steady state under heating test voltage is initially greater than rated voltage, thereby shortening the duration of the test. On the other hand, in the case of the computer simulation, the use of the function corresponding to a gradual increase in power windings and core leads to lengthening its duration.

\section{Simulation results}

On the basis of presented research, object and computational model simulations of the distribution of temperature field in 10 MVA distribution transformer filled with mineral oil, synthetic ester and natural ester were carried out. Figure 3 shows the distribution of temperature field in model of a 10 MVA distribution transformer filled with one of analysed liquid - mineral oil.

Figure 4 shows the temperature distributions in the transformer, on the section of the windings to the inner surface of the tank in the case of three types of insulating liquids. After reaching the steady state of the heat flow maximum temperature in the case of mineral oil equals $65.2^{\circ} \mathrm{C}$, natural ester $66.3^{\circ} \mathrm{C}$ and synthetic ester $66.5^{\circ} \mathrm{C}$. As we can see, the temperature of the liquids in the case of natural ester is $1.1^{\circ} \mathrm{C}$, and in the case of synthetic ester $1.3^{\circ} \mathrm{C}$ greater than mineral oil temperature. Taking into the consideration of the 5 degrees Clark right, which says that the temperature drop or rise of $5^{\circ} \mathrm{C}$ will result in accordingly twice lengthening or shortening life of the transformer insulation paper, these differences are important. This means that the use of natural or synthetic ester as an insulating liquid in transformer will raise the temperature. Consequently, it will contribute to shorten the life of the transformer. 


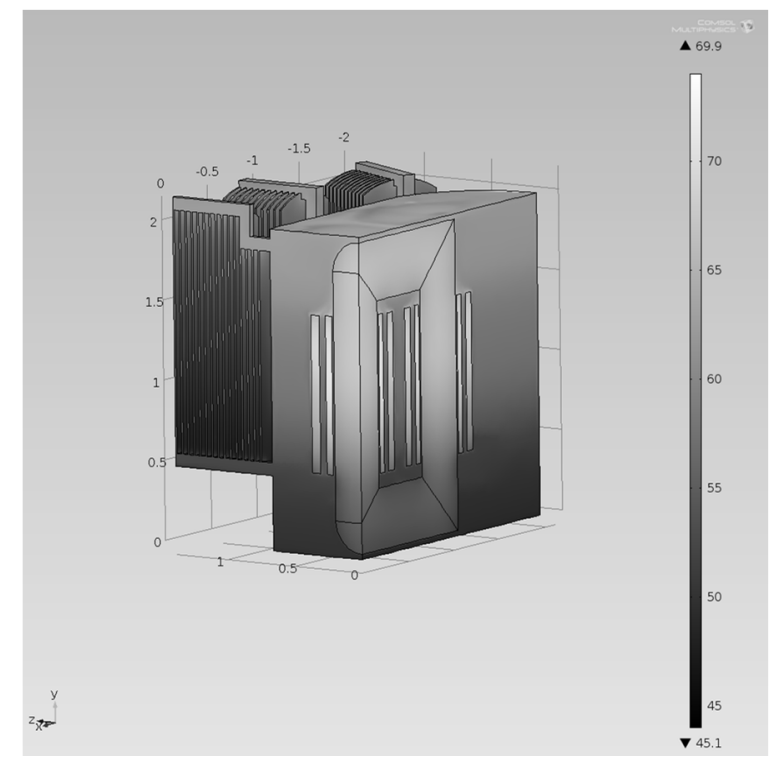

Fig. 3. The distribution of temperature field in 10 MVA distribution transformer filled with mineral oil.

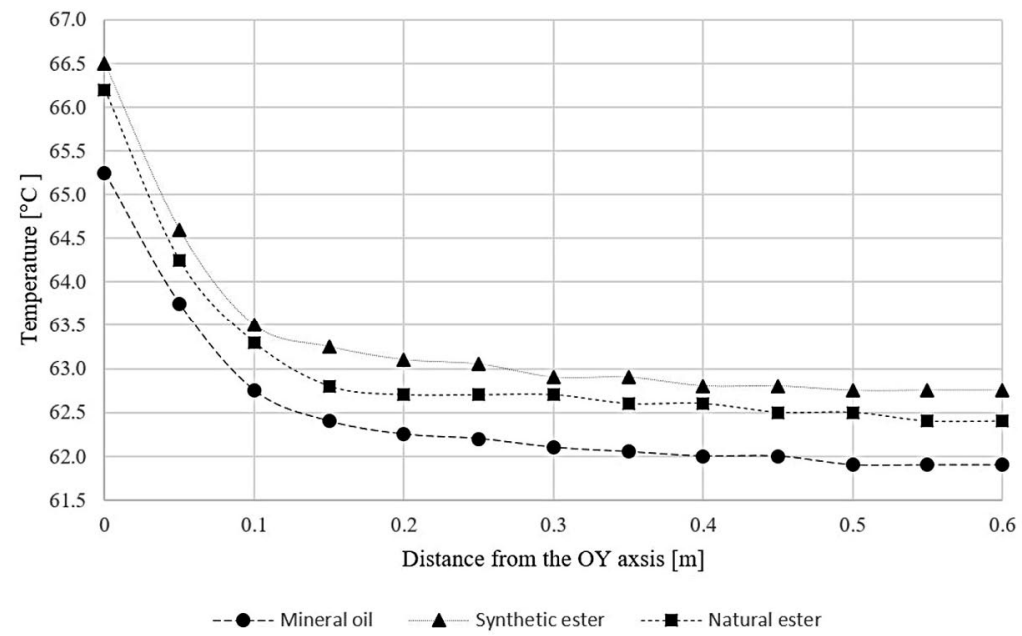

Fig. 4. The distribution of temperature field in a model of 10 MVA distribution transformer in insulating liquid on the section of the windings to the inner surface of the tank, at the height of the inlet to radiator.

\section{Conclusions}

On the basis of received results, we can say that the temperature of the transformer filled with esters is more than $1^{\circ} \mathrm{C}$ higher than the temperature of the transformer filled with mineral oil. In the case of transformer filled with synthetic or natural ester, higher temperature is caused by three times higher viscosity of natural and synthetic esters in relation to the mineral oil. Also, higher temperature will influence negatively the operation of transformers filled esters. 
In the case of power transformers (e.g. $160 \mathrm{MVA}$ ) temperature increase in transformers filled with esters can be even greater as compared to the temperature of the transformer filled with mineral oil. Therefore, in order to use synthetic or natural ester, it should be considered the changing the geometry of the transformer (increasing its size), the reduce of load or the modification of cooling system.

The research was financed from resources of the Ministry of Science and Higher Education for statutory activities No. 04/41/DS-PB/4240, name of the task: The Influence of Various Parameters on Thermal Properties of Dielectric Liquids Used in High Voltage Transformer.

\section{References}

1. T.O. Rouse, IEEE Electr. Insul. Mag., 14, 6-16 (1998)

2. Cigre WG A2.35, Experiences in service with new insulating liquids. Brochure 436 (Cigre, Paris, 2010)

3. E. Gockenbach, H. Borsi, Annual report Conference on Electrical Insulation and Dielectric Phenomena, 521-524 (2008)

4. T.V. Oommen, IEEE Electr. Insul. Mag., 18, 6-11 (2002)

5. T.B. Marchesan, A.J. Fanchin, IEEE/PES Transmission and Distribution Conference and Exposition, 329-333 (2010)

6. P. Thomas, Proceedings of International Symposium on Electrical Insulating Materials, 135-136 (2005)

7. N. Berger, M. Randoux, G. Ottmann, P. Vuarchex, Electra, 171, 33-56 (1997)

8. K. Longva, Nordic Insulation Symposium, 293-295 (2005)

9. C.P. McShane, G.A. Gauger, J. Luksich, IEEE Transmission and Distribution Conference, 2, 890-894 (1999)

10. K. Feser, Z. Radakovic, IEEE T. Power Deliver, 18, 1284-1292 (2003)

11. F. Delgado, A. Ortiz, I. Fernandez, A. Arroyo, J.A. Macias, Electrical Systems for Aircraft, Railway and Ship Propulsion, 1-6 (2012)

12. R. Lopatkiewicz, Z. Nadolny, Przegląd Elektrotechniczny, 84, 50-52 (2008)

13. A. Cichon, S. Borucki, T. Boczar, M. Lorenc, Eur. Phys. J-Spec. Top., 154, 31-38 (2008)

14. R. Lopatkiewicz, Z. Nadolny, P. Przybylek, IEEE International Conference on the Properties and Applications of Dielectric Materials, 1-4 (2012)

15. R. Lopatkiewicz, Z. Nadolny, P. Przybylek, Przegląd Elektrotechniczny, 86, 55-58 (2010)

16. R. Lopatkiewicz, Z. Nadolny, P. Przybylek, W. Sikorski, Przegląd Elektrotechniczny, 88, 126-129 (2012)

17. L. Kasprzyk, A. Tomczewski, K. Bednarek, Przegląd Elektrotechniczny, 86, 57-60 (2010)

18. IEC 60076-2:2011

19. G. Dombek, Z. Nadolny, Eskploatacja i Niezawodnosc - Maintenance and Reliability, 18, 413-417 (2016)

20. Z. Nadolny, G. Dombek, P. Przybylek, IEEE 2016 Conference on Electrical Insulation and Dielectric Phenomena, 857-860 (2016)

21. Z. Nadolny, G. Dombek, P. Przybylek, D. Przadka, IEEE 2016 Conference on Electrical Insulation and Dielectric Phenomena, 538-541 (2016)

22. G. Dombek, Z. Nadolny, Eskploatacja i Niezawodnosc - Maintenance and Reliability, 19, 62-67 (2017) 